\title{
LOS DESAFÍOS METODOLÓGICOS DE LA ETNOGRAFÍA DE LA INTELECTUALIDAD ÉTNICA. REFLEXIÓN COMPARADA DE LOS CASOS PURHÉPECHA Y AYMARA
}

\author{
The Methodological Challenges of the Ethnography of the Ethnic Intelligentsia. \\ Comparative Reflection of the Purhépecha and Aymara Cases
}

\section{JAIME GONZÁLEZ*}

Fecha de recepción: 21 de diciembre de 2017 - Fecha de aprobación: 01 de marzo de 2018

\section{Resumen}

El artículo aborda los desafíos metodológicos que implica hacer etnografía de la intelectualidad étnica. Para ello, se contempla la comparación de dos trabajos de campo elaborados en diferentes áreas de estudio. En el primer caso, se considera la intelectualidad purhépecha en el Estado de Michoacán, México. El segundo caso, aborda los intelectuales aymaras de la región de Arica y Parinacota en Chile. Se concluye que toda etnografía de los intelectuales étnicos, debe estar orientada por una propuesta teórico-metodológica que combine tanto modelos de intelectualidad, como nociones genéricas sobre etnicidad. Solo de esta manera, el investigador dispondrá de los criterios metodológicos de discriminación, tanto para la selección de los sujetos de estudio, como para la definición de los observables que se pretenden registrar.

Palabras clave: etnografía; intelectualidad; etnicidad.

\section{Abstract}

The article addresses the methodological challenges involved in ethnography of the ethnic intelligentsia. For this, the comparison of two field works developed in different areas of study is contemplated. In the first case, the purhépecha intelligentsia is considered in the State of Michoacán, Mexico. The second case, addresses the Aymara intellectuals of the Arica and Parinacota region in Chile. It is concluded that all ethnography of ethnic intellectuals should be guided by a theoretical-methodological proposal that combines intellectuality models as well as generic notions about ethnicity. Only in this way, the researcher will have the methodological criteria of discrimination, both for the selection of the subjects of study, and for the definition of the observables that are intended to be registered.

Keywords: ethnography; intellectuality; ethnicity.

* Dr. en Antropología. Profesor-Investigador en la Universidad Autónoma de Chile, Sede Talca, Chile. Este se enmarca en dos investigaciones de postgrado. La primera, ligada al Programa de Maestría en Antropología Social del Centro de Investigación y Estudios Superiores en Antropología Social (CIESAS)-Unidad Occidente, Jalisco, México. El segundo, vinculado al Programa de Doctorado en Antropología de la Universidad de Tarapacá-Universidad Católica del Norte, AricaSan Pedro de Atacama, Chile. Correo-e: jaime.gonzalez@uautonoma.cl 


\section{1.- Introducción}

El presente artículo es resultado de dos experiencias en trabajo de campo. La primera, ligada al estudio de la intelectualidad purhépecha en la región tarasca del Estado de Michoacán, en México. La segunda, vinculada a la investigación de la intelectualidad aymara en la región de Arica y Parinacota en Chile. $\mathrm{Si}$ bien se trata de dos estudios diferentes en términos de campo analítico, ambas investigaciones se encuentran concatenadas procesualmente por un mismo objeto de indagación: la intelectualidad étnica. En este sentido, los trabajos mencionados apuntaron a investigar los elementos simbólicos de la identidad étnica en intelectuales indígenas, considerando para ello tanto el registro del lenguaje oral y corporal de estos sujetos, como también los contextos sociales del habla y la trayectoria educacional de estos agentes.

Al iniciar esta investigación, nos enfrentamos a preocupaciones disciplinares por parte de pares académicos, producto que el objeto era poco ortodoxo en antropología social. No obstante, y para nuestra fortuna, ya existía importante literatura antropológica que se había hecho cargo de este problema. En este sentido, destacaba la obra de Luis Vázquez León (1992) y Eduardo Zárate (1993), investigaciones que, si bien abordaban el problema de la organización étnica en dos localidades purhépechas, también trataban la presencia de la intelectualidad indígena y su papel en la articulación de esta asociación política. Con perspectivas diferentes, ambos estudios coincidían que estos sujetos cumplían un rol central en la acción étnica de estas colectividades.
Un aporte sustancial se encontró en la obra de María Eugenia Vargas (1994), antropóloga que centró su estudio en esta intelectualidad, formulando un modelo teórico sobre estos sujetos. En este sentido, el esquema formulado contemplaba una tipología clasificatoria con base a dos conceptos básicos. El primero de ellos, definido como "Nueva élite intelectual", ocupado para la investigación de los maestros bilingües tarascos. El segundo, definido como "Intelligentsia nativa", objetivado en el estudio de los profesionales universitarios purhépechas. Con este trabajo, se dispuso de una antropología temprana sobre nuestro objeto, cuyo principal mérito se encontraba en la propuesta de un esquema de análisis sobre la intelectualidad étnica.

Nuevos aportes encontramos en la obra de Willem Assies (1999), estudio colectivo que abordaba el problema de la etnicidad indígena en el continente. Sobre esta base, Assies sostuvo que esta se encontraba vinculada, entre otros factores, a la presencia de una "intelligentsia indígena", fruto de las políticas educacionales del Estado indigenista. De esta manera, la presencia de estos agentes era comprensible por los altos grados de complejidad, estratificación y pluralismo que habían ganado las colectividades indígenas en las últimas décadas. Sin embargo, un estudio esclarecedor para nuestro trabajo de campo en Michoacán, fue la investigación realizada por Natividad Gutiérrez (2001) en una diversidad de casos en México. En esta obra, Gutiérrez formuló un modelo de análisis sobre la intelectualidad étnica con tres variantes fundamentales: 1) intelectual educado (con postgrado), consciente de su cultura étnica (profesor, doctor, conferenciante de seminarios, escritor, editor); 2) miembros educados de la intelligentsia, conscientes de su cultura étnica 
(maestro, empleado civil, lingüista, traductor); 3) intelligentsia no educada, consciente de su cultura étnica (recaudador de fondos, organizador de campañas, técnico, programador de cómputo, periodista con educación de pre-grado y grado académico). En el terreno de la caracterización de los subtipos de este esquema teórico, Gutiérrez sostuvo la presencia de tres elementos fundamentales de los discursos étnicos: a) una tendencia discursiva a elogiar el pasado; b) una protesta para denunciar las condiciones de marginalidad étnica; c) una conciencia de la necesidad que los indios se ocupen de sus asuntos y su destino. Según la autora, los discursos étnicos de estos agentes se caracterizaban por analizar en forma diferente el dualismo modernidad/atraso, ya que respetaban la cultura campesina como fuente primordial de su identidad, sin sentir fascinación o temor por la cultura moderna, debido a que estaban conscientes que esta era la causa de su exclusión y enajenación.

Otros aportes, situados en el debate sudamericano sobre el objeto, fueron de utilidad para esta primera etapa de la investigación. Por una parte, el trabajo realizado por Henri Favre (1996) quien, en el contexto del estudio de la crisis del Estado populista y la emergencia de las organizaciones indianistas, abordó a las dirigencias de estas asociaciones. Sobre esta base, el autor francés formuló su concepto de "intelligentsia lumpenizada". Según Favre, la vuelta a la indianidad, realizada bajo la guía de estos intelectuales, representó un repliegue estratégico para una población que derivaba en la anomia, la cual logró reconocerse y ser reconocida, encontrando un nuevo camino para la acción colectiva.
Por un rumbo diferente, Jorge Gasché (1997), en su estudio sobre la etnicidad indígena en la amazonia peruana, vinculó el fenómeno con las organizaciones internacionales como la ONU, debido a que diversas nociones occidentales tales como "pueblo", "territorio" y "autonomía", discutidas en asambleas y foros de este organismo internacional -estando presentes diversos actores, entre ellos los dirigentes indígenas de la Amazonia peruana - han sido apropiadas por dirigentes étnicos, constituyendo Naciones Unidas una importante influencia intelectual en las propuestas políticas indígenas en relación a dichas nociones. De esta manera, la intelectualidad étnica estaría relacionada con las dinámicas materiales e internacionales del mundo. Sobre esta base se abordó el desafió de hacer etnografía de la intelectualidad étnica en los purhépechas de Michoacán, materia que tratarán las siguientes líneas.

\section{2.- Ruta crítica en torno a la intelectualidad purhépecha}

Si bien el estado del arte sobre la intelectualidad indígena en México y América Latina era amplio y diverso, el problema inicial para etnografiar a nuestros sujetos de estudio se encontraba en la construcción del objeto de indagación. Con base a esta preocupación, nos vimos en la necesidad de abordar una ruta crítica útil para alcanzar este cometido. En función de esta inquietud, consideramos los aportes teóricos generados por Antonio Gramsci (1967) en torno a la definición de intelectual. En este sentido, el pensador italiano nos permitió entender la intelectualidad más como resultado de una condición material, que como producto de la capacidad cognitiva de un 
sujeto. Según Gramsci, todos somos intelectuales por la capacidad humana de pensar, sin embargo, solo algunos se dedican al ejercicio profesional de esta actividad. El hecho estaría ligado a la división social del trabajo, lo que nos permite entender en el intelectual a un individuo ligado a la estratificación social de una colectividad, más que al acceso de éste a la instrucción. Gramsci formula su concepto de "intelectual orgánico", acepción que designa a un grupo de sujetos que dirigen intelectual y moralmente a la sociedad, formando así lo que el autor llama un "bloque histórico", es decir, un concepto que engloba las nociones marxianas de estructura y superestructura, de tal forma que la sociedad es analizada como una forma de dominación.

Contemplamos también la obra de Karl Mannheim (1987), sociólogo alemán que conceptúa a los intelectuales como personas que se caracterizan por conformar un grupo homogéneo, debido al hecho de haber recibido una docencia común y, por tanto, una formación académico-intelectual común, independiente del origen social de estos sujetos. Mannheim define a este grupo como "intelligentsia", y considera que ésta puede cumplir un rol fundamental en la actividad política, debido a que entregan herramientas intelectuales a los grupos y partidos, independiente de su ideología. Según Mannheim, estos individuos no siempre son bien comprendidos debido a su ambivalencia política, hecho que se explica por no constituir una clase social. Por esta característica fundamental, la intelligentsia cuenta con un mayor margen de maniobra al interior de la sociedad, a pesar que no siempre les otorga una posición cómoda.

Un aporte sustancial en la construcción de nuestro objeto lo encontramos en la obra de
Isaiha Berlin (1968). La propuesta del autor eslavo defiende dos nociones dicotómicas: "intelectualidad" e "intelligentsia". Según su formulación, ambos conceptos tienen su origen en el siglo XIX europeo y se caracterizan por una diferencia de contenido. La noción de intelectualidad, de raíz occidental, hacía alusión a un conjunto de individuos cosmopolitas de alta instrucción, dedicados por y para el conocimiento, quienes esperaban ser siempre calificados por su trabajo. La intelligentsia en cambio, fue un concepto de origen ruso, que designaba a un grupo de sujetos parroquiales provenientes de sociedades agrarias, atrasadas y despóticas. La intelligentsia -a diferencia de sus pares occidentales-se caracterizó por combinar avances científicos con una profunda conciencia moral, debido a que éstos observaron en el conocimiento europeo una verdadera fuente de salvación. Para Berlin, ambos grupos de sujetos convivieron en el siglo XIX europeo: los primeros en Europa occidental y los segundos en Rusia. Por tanto, la distinción conceptual que establece el autor entre ambas colectividades considera rasgos espaciales e históricos.

Un valioso aporte a este debate lo encontramos en la obra de Michael Löwy (1979). Para este sociólogo brasileño, los intelectuales se ubican en el plano de la ideología, ámbito social conformado por lo que él llama un "universo de valores cualitativo". De esta manera, el concepto se encuentra situado en las antípodas de la base material de la sociedad, lo que explica que los intelectuales privilegien valores cualitativos, en desmedro de propiedades cuantitativas y economicistas. Según el autor, este entorno intelectual explica tanto el pensamiento de estos agentes como su práctica, lo que puede observarse tanto en su comportamiento 
hablado como en su comportamiento actuado. También nos entrega una tipología clasificatoria de intelectuales. En una apropiación crítica de la obra gramsciana, Löwy sostiene la necesidad de construir un concepto específico sobre estos sujetos. Según su postura, la noción gramsciana de intelectual consideró una categoría más amplia de trabajadores culturales, tales como "empresarios culturales", "distribuidores culturales", "administradores culturales" e "intelectuales". Para Löwy, los empresarios culturales constituyen sujetos dedicados a la industria cultural y al manejo de capitales para el fomento de esta actividad, mientras los distribuidores culturales se caracterizan por la distribución de los productos ideológicos ofrecidos por la industria cultural. Los administradores culturales en cambio, como su nombre lo indica, son individuos dedicados al manejo tecno-administrativo de la cultura ofrecida y distribuida por los anteriores agentes. Sobre esta base teórica, Löwy entrega una definición acotada de intelectual: son aquellos individuos generadores directos de ideología, de tal manera que les asigna una condición eminentemente productiva en el terreno de las ideas.

Una perspectiva conceptual complementaria encontramos en la obra de Ernest Gellner (1998). El científico social europeo aborda en profundidad el problema de los nacionalismos y la etnicidad en Europa, considerando también el papel de los intelectuales en este tipo de fenómenos. Al centrarse en estos últimos, establece un nexo causal entre la actividad del pensamiento y el comportamiento habitual de estos agentes. Según Gellner, la epistemología constituye el punto de partida en el trabajo intelectual de estos individuos. No obstante, la teoría del conocimiento también tiene implicancias en el comportamiento de los intelectuales, ya que los individuos actúan según cómo piensan, por tanto, una postura epistemológica por parte de un intelectual puede generar consecuencias en su acción cotidiana, e incluso en la esfera de la política. De esta manera, existe un vínculo causal entre postura epistemológica de un intelectual y su propio comportamiento, hecho que puede ser observable tanto en su lenguaje oral como en sus prácticas individuales. Al analizar los casos de Ludwing Wittgenstein y Bronislaw Malinowski, dos destacados intelectuales del Imperio Austrohúngaro, Gellner sostiene que el vínculo epistemología-acción puede sufrir modificaciones según la contingencia en la que se encuentre expuesto un intelectual. De esta manera, el comportamiento de estos sujetos depende tanto de la postura epistemológica que presenten, como del contexto social, político e ideológico que estén viviendo. Junto con ello, y en el terreno del análisis de los nacionalismos y la etnicidad, el autor sostiene que ambas variables pueden generar una diversidad de comportamientos políticos en los intelectuales, acciones que pueden variar desde posturas parroquiales y etnicistas, hasta posturas cosmopolitas e individualistas. En este sentido, epistemología y contingencia generan comportamientos simbólicos en estos sujetos, que pueden ser observables en el terreno de la política nacionalista.

Profundizando más en su teoría fundada en los casos de los intelectuales mencionados, Gellner centra el análisis del comportamiento intelectual en la epistemología y como ésta tiene un mayor grado de influencia en la acción de estos sujetos que la misma contingencia. Desde esta perspectiva, el autor sostiene que tanto el comportamiento cosmopolita e individualista, como las prácticas parroquiales y etnicistas, son consecuencia de la oposición 
epistemológica entre "atomismo" y "holismo". Mientras la primera conducta es consecuencia de una postura teórica atomista, la segunda acción es efecto de la epistemología holista. No obstante, esta dicotomía epistemológica, que a ratos pareciera ser bipolar, puede generar una tercera conducta: lo que Gellner llama "el dilema de los Habsburgos". Con este concepto hace alusión a una situación intelectual ligada al tránsito de estos sujetos entre ambas polaridades epistémicas. Desde esta perspectiva, la situación descrita genera un proceso de tensión psicológica en estos individuos, ligada a la filiación de identidades que puedan presentar estos sujetos. De esta manera, el dilema de Habsburgo constituye efectivamente un verdadero dilema de opciones que sufre un intelectual a la hora de elegir una identidad $u$ otra. Según Gellner, este hecho se caracteriza por una tensión entre la filiación cosmopolita de un intelectual, y su nexo parroquial. El dilema consiste en el problema de decidir por qué identidad optar, en un momento de conflicto de lealtades colectivas dentro de la conciencia de un sujeto. En el análisis de la identidad étnica, este dilema tiene efectos relevantes en el campo simbólico, ya que un intelectual puede sufrir esta tensión a la hora de elegir entre una comunidad mayor de una colectividad menor.

Solucionado inicialmente el problema de definir el concepto de intelectual, enfrentamos una segunda dificultad. Esta se vinculaba a la noción de etnicidad, herramienta heurística que nos permitiría disponer de una definición útil de intelectualidad étnica. En este sentido, nos valimos del aporte realizado por Max Weber (2002) con su concepto de "comunidad étnica". La noción propuesta, si bien no desconoce el papel de las condiciones materiales en la formación de comunidades humanas, privi- legia una serie de aspectos simbólicos para comprender otros modos de conformación de grupos sociales. De esta manera, el concepto propuesto por el autor define la etnicidad como un comportamiento ligado a la interacción entre individuos, interacción que permite un intercambio de valores entre las personas, lo que genera una representación colectiva. El autor sostiene que la comunidad étnica constituye tanto una colectividad simbólica, como una etapa en el proceso de conformación de un grupo humano. Así, el concepto caracteriza a la colectividad étnica como una comunidad que cree poseer tanto un origen como un destino común. Según el pensador alemán, la creencia constituye una dimensión relevante sobre todo para la ampliación de las comunidades. Fundándose en la semejanza del hábito exterior y las costumbres, la colectividad étnica se distingue de la familia o del clan -grupos que según el autor constituyen comunidades objetivas- por constituir un "grupo creído". Debido a estos atributos, la comunidad étnica constituye un momento que facilita la cohesión social, sobre todo en el campo de la política.

Un segundo aporte que tributó a esta obra, lo encontramos en el trabajo de Abner Cohen (1969), antropólogo británico que rescató del pasado disciplinar el concepto de "tribu" para investigar a los Hausa en Nigeria. En función de las conclusiones de este estudio, el autor formula dos nociones que aportan a la discusión teórica: 1) por una parte, el concepto de "detribalización"; 2) por otra parte, la idea de "retribalización". Según Cohen, la etnicidad constituye un concepto dinámico que puede expresarse tanto en un sentido progresivo como en uno regresivo, de tal manera que, si observamos a un grupo social viviendo un proceso de etnificación, estamos frente a una dinámica 
de retribalización, mientras que, si observamos la situación contraria, podemos hablar de detribalización. Centrando el análisis en la primera nomenclatura, sostiene que la etnicidad implica un proceso por el cual, bajo ciertas circunstancias estructurales, un grupo étnico manipula valores, normas, creencias, símbolos y formas ceremoniales de su cultura tradicional como arma de lucha política frente a otros grupos.

Complementamos estos aportes, con la valiosa obra de Frédrik Barth (1972), quien aborda la problemática a través de nociones como "etnicidad", "grupo étnico", "organización étnica" e "interacción interétnica". Desde esta perspectiva, el autor noruego define la etnicidad como una serie de categorías de adscripción e identificación que sirven para generar interacción entre grupos humanos. Sobre esta base, Barth considera que estas categorías estaban mediadas por una organización étnica que definía qué sujeto quedaba dentro de la colectividad, y qué actor quedaba fuera de ella. En función de ello, las categorías de adscripción e identificación establecen fronteras entre los grupos étnicos, no obstante, en base a las mismas, generan interacción entre colectividades. De esta manera, el aporte de Barth al concepto de etnicidad es proporcionar una acepción relacional semejante a la formulada por Weber, diferenciándose de ella en relación al hincapié estructural que hace el antropólogo noruego sobre las relaciones humanas.

Con el fin de concluir nuestra ruta crítica, consideramos en su momento la perspectiva teórica más avanzada que estaba a disposición. Nos referimos a la obra de Sinisa Malesevic (2004), autor serbio que propuso analizar el concepto a través de la síntesis de dos teorías que consideró útiles: 1) la "teoría clásica de élites"; 2) la "teoría neoweberiana de élites de la etnicidad". La teoría clásica de élites constituye una corriente de la sociología política que sostiene que, independiente de los cambios políticos o económicos sufridos por las sociedades a través del tiempo, lo que permanece constante en toda formación social es la presencia de una élite que controla los destinos de la colectividad. De esta manera, a pesar de que un proceso político genere el fin del control por parte de una élite, la misma dinámica conducirá inevitablemente a la instalación de un nuevo grupo con similares características. Si bien las distintas variables que privilegia esta teoría para explicar esta afirmación, lo medular del argumento sostiene que toda sociedad genera sus propias élites. Por lo demás, todo cambio social, por muy radical que este sea, no implica otra cosa que la renovación de éstas, o incluso el cambio de una élite por otra (Malesevic, 2004). La teoría neoweberiana de élites de la etnicidad constituye un enfoque que combina elementos propios del análisis de Max Weber con ópticas que privilegian variables geopolíticas para comprender el fenómeno étnico. Sobre esta base, la perspectiva teórica establece una distinción conceptual entre "etnia" y "grupo étnico", donde la primera es definida como un tipo de comunidad, mientras la segunda es entendida como una forma de asociación política. Desde esta perspectiva, la etnicidad constituye un fenómeno conformado tanto por variables endógenas -grupos étnicos dentro de un Estado nación-como por factores exógenos de carácter internacional, de tal manera que estos últimos se asocian a la acción política de élites de otros países. Así, a los conflictos políticos internos a un Estado, generados por agentes y grupos sociales en pugna, se suman las percepciones y acciones 
de actores externos que pueden variar desde grupos de presión hasta estados nacionales.

Sobre la base de esta síntesis teórica, Malesevic (2004) define la etnicidad como un concepto político, entendiendo a los "grupos étnicos" como organizaciones sociales estratificadas, donde destaca la dirigencia de una intelectualidad étnica con alta instrucción. Estos intelectuales se caracterizarían por manejar la identidad de grupo para defender intereses concretos, e interactuarían con otras élites dentro de un contexto político más amplio -que incluiría desde el ámbito nacional hasta la esfera internacional- hecho que restaría parcialmente la autonomía de estos sujetos. Según el autor, en los últimos años la etnicidad se aprecia diferente que en el pasado, ya que se observa políticamente fragmentada y se expresa en forma diversa al interior de los grupos sociales e incluso entre los mismos individuos. Desde esta perspectiva, Malesevic considera que estamos frente a un proceso de "individuación" de la etnicidad, lo que tiene como consecuencia que entendamos el actual fenómeno a través de un concepto que centre el análisis en el comportamiento individual de los sujetos y sus respectivas interacciones intersubjetivas.

Siguiendo esta ruta crítica, formulamos nuestra propuesta teórico-metodológica en torno al estudio de la intelectualidad purhé. En este sentido, el trabajo de campo contempló el segundo semestre de 2005, considerando esta primera propuesta de modelo de intelectualidad étnica para la definición de los sujetos de estudio. Para la definición de las unidades de observación, se combinó este esquema de análisis con los conceptos de "encuentro", "idioma corporal" y "conciencia discursiva" tributarios de la teoría de la estructuración (Giddens, 2003). A esto sumamos los aportes metodológicos del análisis de la conversación y la etnografía del habla (Moerman, 1991; Coulón, 1998), para disponer de una propuesta teórica y metodológica útil en campo. De esta manera, la etnografía era entendida como un trabajo dialogal, dinámico e intersubjetivo, que apuntaba al registro de voces y comportamientos actuados de los informantes. En el plano operativo, nos valimos de la entrevista semi-estructurada, procedimiento que nos permitió flexibilizar la recolección de datos en función de la situación social de entrevista. De esta forma, se combinó tanto el registro de voces, como la observación del contexto social del habla, para dar cuenta de la visión de estos intelectuales sobre la identidad de su etnia.

Con base a este procedimiento general y específico, realizamos el trabajo de campo en múltiples localidades de la región purhépecha en Michoacán. La condición semi-nómade de los sujetos de estudio, nos condujo a un registro en movimiento que nos permitió etnografiar a los individuos en su vida cotidiana, fuera esto en el trabajo, en su domicilio o en un lugar de esparcimiento. La elección de los lugares de entrevista fue definida por la preferencia o gusto de los participantes de la investigación. El resultado de esta estrategia fue un abultado corpus discursivo, registrado mediante entrevistas que contemplaron al menos una hora de duración.

La reflexión final en torno a este trabajo de campo, arrojó una serie de lecciones a la hora de hacer etnografía de la intelectualidad étnica. La primera de ellas apuntaba abiertamente a la ruta crítica de la investigación. En este sentido, la investigación de estos sujetos nos exigía el empleo de teorías que establecieran el equilibrio entre estructura y acción. De esta manera, los modelos de análisis que privilegiaran 
propiedades constrictivas del comportamiento, generarían impactos negativos en el registro de datos simbólicos.

Una segunda lección se vinculaba al hecho de comprender, que la etnografía de estos sujetos debía contemplar el complejo papel que cumple el etnógrafo en la construcción de los datos. En este sentido, el procedimiento de registro debía hacer mayor hincapié en la condición intersubjetiva del conocimiento antropológico. Una tercera lección se vinculaba al problema de la identidad étnica. En este terreno, si bien la investigación estudió la identidad étnica desde la voz de los sujetos de estudio, nuestro marco teórico no logró problematizar lo suficiente esta dimensión del objeto. Fueron estos aprendizajes los que se trasladaron a un nuevo terreno de indagación: la intelectualidad aymara en Chile.

\section{3.- Ruta crítica en torno a la intelectualidad aymara}

Las lecciones aprendidas en Michoacán fueron consideradas a la hora de realizar un estudio de la intelectualidad aymara en Chile. La investigación en este nuevo campo analítico contempló el debate sudamericano, haciendo un importante hincapié en la antropología realizada en Chile. En este terreno, aportó de manera relevante la obra de Xavier Albó (2005) en el ámbito de la etnicidad indígena. Ocupando una antigua formulación marxiana aplicada a la teoría de clases sociales, Albó sostenía que los aymara constituyen una nación en sí, más no una nación para sí. Desde esta perspectiva, el fenómeno se encontraba vinculado a la heterogeneidad de las poblaciones indígenas, donde la distinción entre las bases sociales de la etnia y lo que él llama la "intelligentsia aymara" se hacían evidentes. A este hecho se suma el sentimiento de pertenencia de la colectividad, fenómeno que se asocia más a la cultura o a la economía, que a una identificación mayor como sería la nación étnica. Según Albó, existen embriones de esta variable más o menos fuertes según país o región, y sectores organizados en que sí existe una conciencia y voluntad al respecto. No obstante, el hecho no constituye una propiedad generalizable en esta frontera trinacional. El fenómeno variará según la política local y municipal vigente (Albó, 2005), lo que podría explicar ciertos síntomas de fragmentación orgánica en la etnicidad indígena.

En el caso de Chile, nos aportó en forma considerable la investigación doctoral realizada por Beatriz García Traba (1997). En el extremo norte nacional, García sostiene que, en las conversaciones de los dirigentes indígenas con el Estado, la Iglesia, las ONGs, se produce una "negociación de la identidad". Por tanto, no existe una claudicación por la no utilización del término "pueblo" o por emplear otros conceptos aparentemente menos apropiados o suaves, sino que se negocia con las distintas instituciones, con el fin de ir preparando a la sociedad chilena para futuras reivindicaciones. En otro plano, la autora sostiene que no existe una dependencia de ONGs, Iglesia o Estado, sino una utilización de su infraestructura para planificar futuras demandas. De esta manera, la etnicidad aymara se presenta discursiva y simbólica, estratégica, instrumental y negociadora en sus planes de avance político e ideológico en el ámbito regional.

Otros estudios que fueron fundamentales para aproximarnos al campo analítico, y a nuestro objeto, fueron los trabajos de Hans 
Gundermann y Jorge Iván Vergara (2009, 2012). En este terreno, en su investigación sobre la organización étnica aymara y atacameña, sostienen que estas entidades son resultado de la interacción entre éstas y las agencias estatales chilenas. De esta manera, la etnicidad indígena se presenta como un tipo de relación social, que se entiende dentro de un campo de fuerza que puede oscilar entre la dimensión local y el ámbito municipal, destacando en los últimos años la dialéctica organización étnica-acción estatal en la formación de la identidad indígena (Gundermann \& Vergara, 2009). En otros estudios, Gundermann y Vergara formulan su concepto de "campo identitario regional”, propuesta teórico-metodológica que les permite estudiar el "lugar social" de la identidad indígena en un contexto social regional. De esta manera, la identidad de estos grupos constituye una sub-identidad de una realidad mayor: la identidad regional. Será en esta contingencia que los autores entenderán la identidad como un concepto relacional, donde lo indígena dependerá del contexto simbólico de la sociedad mayor (Gundermann \& Vergara, 2012). En posteriores investigaciones, esta perspectiva gana en complejidad al considerar esta realidad de manera evolutiva. En este sentido, la valoración positiva de la condición de "indio" por parte de un conjunto de jóvenes profesionales urbanos, establecería el nexo entre etnicidad, identidad e intelectuales indígenas (González, Gundermann \& Hidalgo, 2014). Según esta visión, los profesionales indígenas serían sujetos ligados a la generación de las primeras organizaciones étnicas regionales que lograron insertarse y mantener alianzas con el movimiento indígena del resto del país. Este grupo de profesionales indígenas logró controlar la Corporación de Desarrollo Indígena con posterioridad al proceso de redemocratización vivida en Chile entre 1988 y 1990, y presenta en la actualidad una importante participación en la escena política regional, debido a que a través de sus organizaciones controlan la relación política con el Estado, posición privilegiada considerando que el Gobierno discrimina positivamente a los indígenas a través de iniciativas legales, administrativas y, no siendo menos relevante, a través de la canalización de recursos.

No obstante, lo mencionado anteriormente, los estudios más iluminadores para este trabajo de campo estuvieron ligados a la obra de Claudia Zapata (2005; 2007a; 2007b; 2008). Su investigación sobre la intelectualidad indígena en Chile y América Latina desde sus prácticas escriturales aportó una nueva dimensión al objeto. En este sentido, esta práctica observada lo encuadra en una tipología clasificatoria de intelectuales de tipo "orgánico y semi-orgánico" (Zapata, 2005). De esta manera, Zapata identifica tres tipos de intelectual indígena: 1) intelectual dirigente; 2) intelectual profesional; 3) intelectual crítico. En base a esta clasificación, la autora analiza los escritos de intelectuales aymara del norte chileno, estableciendo el problemático vínculo entre memoria indígena e identidad colectiva (Zapata, 2007a). La tesis que resulta de este análisis, sostiene que la identidad étnica surge como un fenómeno reciente, donde los sujetos involucrados principalmente aymaras urbanos - sienten la necesidad de estructurar una memoria representativa de este grupo. Desde esta perspectiva, la memoria cumple la función de crear anclajes temporales y espaciales a la identidad, permitiéndole a ésta el control sobre el pasado y la legitimación de su existencia. Las prácticas escriturales de esta intelectualidad, dan cuenta de una defensa ideológica de la cultura indígena 
que se opone, primordialmente, a la hegemonía occidental. En su introducción a la obra "Intelectuales indígenas piensan América Latina" (Zapata, 2007b), la autora sostiene:

\begin{abstract}
Una característica que nos llama la atención de estos autores, es que la investigación y el lugar de la escritura constituyen el punto de partida para un trabajo que no es y que no puede ser neutral. Es así como sus formas de enunciación y la construcción de un "yo indígena" que recorre varios niveles -el de la comunidad, el del grupo étnico y el de un colectivo continental- configuran un desplazamiento teórico y epistemológico al interior de disciplinas que suponen en la objetividad y en la distancia narrativa una prueba de rigurosidad. (p. 13).
\end{abstract}

Centrando el análisis en los "intelectuales críticos", Zapata (2008) sostiene que el discurso escrito de estos sujetos, se vale de herramientas y tecnologías que en el pasado sirvieron para dominarlos. Las prácticas escriturales de estos individuos, dan cuenta de un proyecto político que instrumentaliza el conocimiento disciplinar, para defender la descolonización de la cultura en los países latinoamericanos. De esta manera, independiente de las tensiones culturales que presenten estos sujetos en su vínculo con la sociedad mayor, la práctica intelectual indígena pasa por levantar un proyecto histórico para estos grupos en la escena continental.

Con base a este estado del arte, retomamos la ruta crítica del anterior trabajo de campo para realizar los ajustes correspondientes en función de las lecciones aprendidas. Quizás la mayor dificultad en torno a ellas, fue abordar la debilidad teórica de nuestro objeto en el terreno de la identidad étnica. Este aspecto logró subsanarse mediante el concepto de "identidad colectiva" formulado en la obra de Amartya Sen (2008 [2007]). Según el economista indio, la identidad se entiende como un sentimiento de filiación que puede ser individual o colectivo. Centrando el análisis en la última filiación, Sen sostiene que el concepto cuenta con dos dimensiones: 1) la primera, que el autor define como "identidad plural"; 2) la segunda, que Sen llama "identidad singular". Desde esta perspectiva, se entiende la primera dimensión como la condición natural de los seres humanos, ya que todo individuo se encuentra afiliado a múltiples grupos sociales, tales como ser hombres, padres de familia, profesionales, maridos, miembros de una religión, integrantes de una región en particular, miembros de una nación e incluso tener una filiación político-partidaria. En función de esta condición observamos que toda identidad colectiva es plural, lo que tiene como consecuencia que cada individuo sea diferente de otro debido a sus múltiples filiaciones colectivas. La identidad singular en cambio constituye una dimensión diferente, que hace alusión a la pérdida de las múltiples dimensiones de la identidad colectiva, para dejar en su lugar una suerte de etiqueta unidimensional. Según Sen, esta identidad entra en escena cuando interviene la política organizada en el terreno simbólico, lo que trae como consecuencia que el mundo viva una serie de hechos de violencia debido a la condición singular de esta identidad. Dicho en otras palabras, la identidad singular en Sen es una etiqueta política, que sirve como bandera o símbolo de distinción para participar en la arena del poder.

Considerando el trabajo teórico alcanzado en la anterior investigación, más los ajustes para este nuevo desafío, logramos reformular nuestro modelo de intelectual étnico. En este sentido, el objeto fue entendido como un conjunto de sujetos dedicados al ejercicio profesional de la 
inteligencia. Junto a esta definición genérica, se aportó también un concepto más acotado: la intelectualidad étnica presenta una serie de atributos complejos, ya que, producto tanto de la epistemología en la que fundan su comportamiento, como por los grados y tipos de instrucción adquirida, pueden presentar comportamientos parroquiales y etnicistas, propios de la intelligentsia, como también pueden mostrar conductas individualistas y cosmopolitas, propios de la intelectualidad. Desde esta perspectiva, no se excluían en los subtipos prácticas intermedias entre ambas polaridades, como podrían ser los actos de tipo administrativo de los profesionales de la inteligencia. A esto se sumaba teóricamente la dinámica de la condición de los sujetos de estudio. De esta manera, nuestro entendimiento del concepto de intelectualidad pretendía identificar más tendencias intelectuales en los sujetos, que clasificaciones fijas en los individuos. Por lo mismo, desde nuestra postura, un miembro de la intelectualidad puede presentar tres tipos de comportamiento -actuado o hablado- en su vida intelectual: 1) como intelectual; 2) como administrador cultural; 3) como intelligentsia. Entendemos por el primer comportamiento la acción intelectual definida por Berlin y Löwy, es decir, como sujetos dedicados por y para el conocimiento, mientras la segunda conducta se funda en el concepto de administrador de la cultura formulado por Löwy. Por último, la tercera práctica fue entendida en esta etapa de la investigación según la formulación de Berlin sobre el concepto de intelligentsia. En cuanto a las posibles causas de esta variedad de tendencias en el comportamiento intelectual, consideramos tres factores fundamentales: a) los grados y tipos de instrucción; b) la epistemología en que fundan su actuar; c) la contin- gencia interactiva de sus propios actos. De esta manera, la identidad étnica que generen los intelectuales indígenas -que tienen la particularidad de ser intelectuales étnicos- dependerá de estas tres variables.

La nueva investigación entendía la etnicidad como un tipo de acción política basada tanto en el simbolismo como en la organización social de la diferencia grupal, de tal manera que la organización de la diferencia cumplía un papel central para la defensa de intereses concretos. Entendíamos por identidad étnica un tipo de representación colectiva que se distingue de otras por el manejo simbólico de la diferencia grupal con el fin de defender intereses concretos. De esta manera, ambas acepciones fueron definidas según las dinámicas del poder, donde la interacción con otras colectividades cumple un papel fundamental. Así, siguiendo los lineamientos de los enfoques constructivistas que centran el análisis en el simbolismo, se definieron ambos conceptos como nomenclaturas relacionales que se entienden en función de interacciones individuales y colectivas. Con esto no se desconoció la dimensión material de las comunidades humanas. Lejos de ello, analizamos la etnicidad y la identidad étnica desde una perspectiva simbólica, pero situada dentro de una contingencia económica y política concreta. En el fondo, nuestra diferencia con las perspectivas materialistas, radicó en ese momento más en los énfasis en el análisis, que en elementos fundamentales con estas aproximaciones.

Con base a este ajuste en la ruta crítica, se hicieron modificaciones para la nueva propuesta de etnografía de la intelectualidad étnica. Retomando las lecciones aprendidas en el anterior estudio de caso, se hizo hincapié en la condición intersubjetiva de la investigación, 
considerando los conceptos de "encuentro de investigación" formulado por Luis Vázquez León (2003), y "encuentro comunicativo" elaborado por Gustavo Lins Ribeiro (2014). En el caso del primer aporte, el autor mexicano sostiene que el "hecho de observar" y el "hecho de participar" en la investigación esconden un dilema: ambos componentes del método etnográfico están siendo disociados y opuestos por una contingencia inédita, en que los tradicionales objetos de estudio se están erigiendo ellos mismos en sujetos de conocimiento, negándose por ello a mantener una relación instrumental como "meros informantes" de los antropólogos. Según Vázquez León (2003):

me resulta de enorme interés la modalidad de entrevista que denominan "encuentro de investigación", cuya forma depende precisamente de la relación establecida entre los interlocutores, pero que admite la posición influyente del actor, hasta el punto de que el tópico de conversación puede derivar del sujeto al objeto, que de ese modo expresa sus intenciones, intereses e interpretaciones. (p. 41)

Desde esta perspectiva, el antropólogo mexicano defiende el concepto giddeniano de "doble hermenéutica" (Vázquez León, 2002), entendiendo la etnografía del habla como un encuentro dialogal en que investigador e investigado se interpretan en forma intersubjetiva. El énfasis en la situación de encuentro y doble hermenéutica resultaba clave para su propuesta teórico-metodológica ya que, considerando que su objeto de estudio era el lenguaje de intelectuales profesionales, la capacidad de interpretación de estos agentes implicaba un problema metodológico que no se presenta en sujetos de baja instrucción.

Esta perspectiva teórica y metodológica sobre el modo de estudiar el lenguaje, concuerda con una aproximación etnográfica ligada al estudio de los sujetos en general formulada por Gustavo Lins Ribeiro y Robert V. Kemper (2014). Esta perspectiva, fundada en la teoría de la estructuración, centra su propuesta en la noción de "encuentro comunicativo". Según sus propias palabras:

La etnografía se sostiene tanto en los intercambios objetivos como en los intersubjetivos que ocurren durante el trabajo de campo y, como tal, la mejor forma de comprenderla es como una serie de encuentros comunicativos en los que los participantes ansían tener bajo control y, eventualmente, minimizar la ignorancia que comparten sobre situaciones de campo particulares. La noción de extrañamiento es crucial para este argumento. Se refiere a la conciencia de que tanto los investigadores como aquellos que son investigados sienten que viven/experimentan interacciones torpes, en particular porque los participantes en el encuentro etnográfico típicamente no reproducen sus encuentros comunicativos rutinarios ni sus actos de habla cotidianos. Mientras en el campo los antropólogos y las antropólogas están fuera de sus espacios cotidianos y deben monitorear sus nuevas relaciones, se exponen a situaciones donde su "conciencia práctica" —es decir, todas las cosas que los actores saben de forma tácita (Giddens, 1984)— es temporalmente incapaz de interpretar con precisión nuevos entornos y nuevos sujetos. Esta incapacidad obliga a los etnógrafos a reforzar su proceso perceptual y cognitivo en negociaciones con las otras personas, quienes a su vez ansían "domesticar" a esos extraños inquisitivos. (p. 64)

El lenguaje es comprensible en un encuentro de comunicación, donde se ponen en juego una serie de prácticas cotidianas ejercidas por los agentes participantes, con el fin de mantener el control de la situación de copresencia. Desde esta perspectiva, el lenguaje es comprensible, y explicable, en función de contextos dialógicos, donde la misma investigación etnográfica forma parte de los procedimientos metódicos con los cuáles entramos en contacto, generamos rapport, y comenzamos el registro de los datos. 
De esta manera, nuestra propuesta etnográfica establecía un maridaje entre la teoría de la estructuración (Giddens, 2003), el análisis de la conversación (Moerman, 1991; Coulón, 1998) y la propuesta metodológica de Vázquez (2003) y Lins Ribeiro (2014). El estudio contemplaba una serie de unidades de observación situadas a nivel contextual e intersubjetivo. Por otra parte, la misma propuesta nos proporcionaba herramientas útiles para el registro del lenguaje, en una dimensión oral y corporal. De esta forma, se entendía el lenguaje oral y corporal de los sujetos de estudio como prácticas comunicativas, procedimientos metódicos que son empleados para interactuar con otros agentes, incluso en una situación de entrevista. Sobre esta base definimos una serie de observables útiles para la investigación. Así, elaboramos una serie de unidades de observación en los núcleos urbanos de Arica y Putre, en los cuáles se contempló: 1) sujetos típicos; 2) espacios característicos (cosmopolita o parroquial: ciudad-organismo público o académico; pueblo de origen y sus espacios de interacción). El trabajo de campo se realizó durante el período estival del año 2010.

Al finalizar el trabajo de campo, realizamos una reflexión sobre este estudio de caso. Los aprendizajes ganados en esta nueva experiencia, estuvieron vinculados al problema de establecer equilibrios entre estructura y acción a la hora del registro. En este sentido, el esfuerzo por registrar el contexto social mayor en que están situados los sujetos de estudio superaba las energías del investigador. A esto se sumó la complejidad que implicaba estudiar sujetos de alta instrucción y con capacidad de observación a la hora de hacer etnografía. Sobre esta misma dificultad, se hizo evidente el problema del tiempo cronológico en el terreno de la investigación. En este sentido, resulta un desafío metodológico evaluar cuál es el "tiempo adecuado" para una etnografía de la intelectualidad étnica, considerando el fraccionalismo social y las dificultades de alineamiento político en torno a la generación de identidades étnicas. En el presente se nos integra un nuevo desafío que no era evidente durante esta última experiencia de investigación. Nos referimos al problema de estudiar esta intelectualidad étnica en tiempos de migración extranjera. En este sentido el "lugar social" de la identidad, y de estos sujetos, dependerá de una contingencia regional y nacional que ha ganado en complejidad, producto de los nuevos diálogos interculturales e interétnicos.

\section{4.- Reflexiones finales}

A modo de finalizar este trabajo, y considerando los aprendizajes ganados en dos áreas de estudio diferentes, contemplamos algunas conclusiones metodológicas. Las reflexiones de ambos trabajos en terreno, nos orillan a pensar en los nuevos desafíos que se deben afrontar a la hora de realizar futuras etnografías de la intelectualidad étnica. Considerando sobre todo la reflexividad que realizamos en nuestro último estudio, estimamos que las futuras aproximaciones al objeto deben contemplar aspectos estructurales, microscópicos, temporales y culturales.

Una primera inquietud metodológica está ligada al problema del registro de información social a escala regional. En este sentido, pensamos que los próximos estudios sobre la intelectualidad étnica, deben explorar los posibles aportes que pueda proporcionar la etnografía palermiana (Pérez Lizaur, 2014) para 
la observación de contextos sociales mayores. En este sentido, los equipos de investigación podrían definir nuevos caminos para la recolección de información social extra-local. Consideramos que se debe contemplar la posibilidad de combinar la etnografía palermiana con la etnografía multi-local formulada por Georges Marcus (2001). Es posible que esta estrategia, facilite el registro del contexto social regional de la intelectualidad étnica.

A nivel microscópico, consideramos necesario estimar el papel de los procesos de interacción individual e interacción colectiva, para el entendimiento más profundo del comportamiento de la intelectualidad étnica. De esta manera, podríamos evaluar la etnografía como "encuentro comunicativo" (Lins Ribeiro, 2014), y el impacto que la doble interpretación genera en el registro de los datos. En otro plano, consideramos necesario explorar el papel del "tiempo adecuado" para una etnografía de la intelectualidad étnica, sobre todo considerando el fraccionalismo social y las dificultades de alineamiento

\section{Notas}

${ }^{1}$ El artículo fue presentado originalmente como ponencia en las "Primeras Jornadas de Etnografía" efectuadas en la Universidad Academia de Humanismo Cristiano, entre los días 27 y 28 de noviembre de 2017. El autor agradece el apoyo recibido por el

\section{Referencias bibliográficas}

Assies, W. (1999). Pueblos indígenas y reforma del Estado en América Latina. En Assies, W., Van der Haar, G. \& Hoekema, A. (Ed.), El reto de la diversidad (pp. 1-16). Zamora, Mich: El Colegio de Michoacán.

Albo, X. (2005). Alcaldes y munícipes indígenas en Bolivia, 2002. La Paz: CIPCA.

Berlin, I. (1968). The Power of Ideas. Princeton, New Jersey: Princeton University Press.

Barth, F. (1972). Los grupos étnicos y sus fronteras. México: FCE. político en torno a la generación de identidades étnicas. Así, si la etnografía se convierte en una forma de generar fotografías sociales, nos vemos en la necesidad de afrontar los problemas metodológicos que implica abordar a estos sujetos en contextos de identidad plural.

En el plano cultural, consideramos necesario contemplar el comportamiento escritural de la intelectualidad étnica. El estudio de los textos escritos de estos agentes, nos permitirá registrar una nueva dimensión de los elementos simbólicos de la identidad étnica en estos sujetos. Por último, resulta necesario repensar la observación directa, e indirecta, de los contextos sociales intersubjetivos del habla. En este sentido, y pensando en la noción de "integración social" de Giddens (2003), consideramos que la investigación de la intelectualidad étnica debe afrontar el gran desafío de estudiar a estos sujetos, contemplando los actuales tiempos de migración extranjera en áreas indígenas de Chile. De todo esto se deberá hacer cargo la futura etnografía de los intelectuales étnicos.

programa de maestría a través de una BECA-CIESAS, así como también el respaldo de una BECA UTA-MECESUP por parte del programa de doctorado.

Cohen, A. (1969). Custom and politics in urban Africa. Berkeley: University of California Press.

Coulon, A. (1998). La etnometodología. Madrid: Cátedra.

Favre, H. (1996). El indigenismo. México: FCE.

Gramsci, A. (1967). La formación de los intelectuales. México: Grijalbo.

Gasché, J. (1997). Educación intercultural vista desde la amazonia peruana. En Bertely Busquets, M. \& Robles Valle, A. (Coord.), Indígenas en la escuela (pp. 147-158). México: Consejo Mexicano 
de Investigación Educativa.

Gutiérrez, N. (2001). Mitos nacionalistas e identidades étnicas: los intelectuales indígenas y el Estado mexicano. México: CONACULTAIIS- Editorial Plaza y Valdés.

Giddens, A. (2003). La constitución de la Sociedad: bases para la teoría de la estructuración. Buenos Aires: Amorrortu.

Gellner, E. (1998). Language and Solitude. Wittgenstein, Malinowski and the Habsburg Dilema. Cambridge: Cambridge University Press.

Gundermann, H. \&Vergara, J. (2009). Comunidad, organización y complejidad social andinas en el norte de Chile. Estudios Atacameños, (38), 107-126.

(2012). Conformación y dinámica interna del campo identitario regional en Tarapacá y Los Lagos, Chile. Chungara, 44(1), 115-134.

González, H., Gundermann, H. \& Hidalgo, J. (2014). Comunidad indígena y construcción histórica del espacio entre los aymara del norte de Chile. Chungara, 46(2), 233-246.

García, B. (1997). El discurso político de las organizaciones aymaras del norte de Chile. (Tesis inédita de doctorado). Universidad Complutense de Madrid, Facultad de Geografía e Historia, Madrid.

Löwy, M. (1979). Para uma sociologia dos intelectuais revolucionários. A evolucao política de Lucács (1909-1929). Sao Paulo: Lech Livraria Editora Ciencias Humanas.

Lins Ribeiro, G. \& Kemper, R. (2014). Ángel Palerm y el trabajo de campo: un legado que perdura. Desacatos, (45), 63-67.

Marcus, G. (2001). Etnografía en/del sistema mundo. El surgimiento de la etnografía multilocal. Alteridades, 22(11), 111-127.

Malesevic, S. (2004). The Sociology of Ethnicity. USA: Sage Publications.

Moerman, M. (1991). Talking Culture. Ethnography and Conversation Analysis. Pennsylvania: University of Pennsylvania Press.
Mannheim, K. (1987). Ideología y utopía. Introducción a la sociología del conocimiento. México: FCE.

Pérez, M. (2014). De Franz Boas a Ángel Palerm. Desacatos, (45), 13-26.

Sen, A. (2008). Identidad y violencia. La ilusión del destino. Buenos Aires: Katz Editores.

Vargas, M. (1994). Educación e ideología. Constitución de una categoría de intermediarios en la comunicación interétnica. El caso de los maestros bilingües tarascos (1964-1982). México: CIESASColección Miguel Otón de Mendizábal.

Vázquez, L. (1992). Ser indio otra vez. La purepechización de los tarascos serranos. México: CONCULTA.

(2002). Quo vadis anthropologia sociales? En De la Peña,

G. \& Vázquez León, L. (Coord.), La antropología sociocultural en el México del milenio. Búsquedas, encuentros y transiciones, México: INI-CONACULTA-FCE.

(2003). El Leviatán arqueológico. Antropología de una tradición científica en México. México: CIESAS-Miguel Ángel Porrúa.

Weber, M. (2002). Economía y sociedad. México: FCE.

Zárate, J. (1993). Los señores de utopía. Zamora-México: COLMICH-CIESAS-México.

Zapata, C. (2005). Origen y función de los intelectuales indígenas. Cuadernos interculturales, volumen 3(4), 65-87. (2007a). Memoria e Historia: El proyecto de una identidad colectiva entre los aymaras de Chile. Chungara, 39(2), 171 - 183. (2007b). Intelectuales indígenas piensan América Latina. Quito: Universidad Andina Simón Bolivar-Ediciones ABYA YALACentro de estudios culturales latinoamericanos, Universidad de Chile. (2008). Los intelectuales indígenas y el pensamiento anticolonialista. Discursos/prácticas, (2), 113-140. 